\title{
The 17th Annual Congress of the European Pediatric Surgeons' Association
}

\author{
Tomas Wester $^{1}$ \\ ${ }^{1}$ Department of Pediatric Surgery, Karolinska University Hospital, \\ Karolinska Institutet, Stockholm, Sweden \\ Eur J Pediatr Surg Rep 2016;4:i.
}

The 17th Annual Congress of the European Paediatric Surgeons' Association (EUPSA) was organized in Milano in June 2016. For the first time a dedicated session of case reports was on the program. It was possible to submit abstracts specifically for the case report session. Total 168 case reports were submitted and 18 of these were selected for the oral case report session. In addition, two poster walks were dedicated to case reports.

Authors of accepted abstracts were invited to submit a manuscript to European Journal of Pediatric Surgery (EJPS) Reports. Selected papers of high quality are now included in the current issue of EJPS Reports. The papers cover a wide range of topics and include descriptions of rare cases as well as innovative surgical techniques. The papers are published free of charge, which can help open up the research of young EUPSA scientists to a wider audience. The format of open access has the advantage that articles are freely available for anyone who wishes to read them, also in countries with limited opportunities to subscribe to international journals.

The experience with this year's case report session was very good. There will be a dedicated case report session again during the 18th EUPSA Congress in Limassol, Cyprus, to be held on May 17 to 20, 2017.
Address for correspondence Tomas Wester, MD, PhD,

DOI http://dx.doi.org/ 10.1055/s-0036-1597566. Chairman of the EUPSA Scientific ISSN 2194-7619. (c) 2016 Georg Thieme Verlag KG Stuttgart · New York
License terms

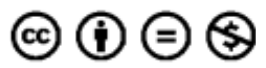

Office, Department of Pediatric

Surgery, Karolinska University Hospital, Karolinska Institutet, Solna, S3:02, 17176 Stockholm, Sweden (e-mail: tomas.wester@karolinska.se). 